\title{
MANIFESTO FOR THE ROMANIAN PUBLIC ARCHAEOLOGY
}

\begin{abstract}
In this paper I shall only discuss a few of the problems of archaeology in Romania from the perspective of my one-year experience as member and vice-president of the National Commission of Archaeology. My goal here is to attempt to systematize the discussions during the meetings and round tables of the year that has just passed. The meetings were held in Bucharest, in the building of the Ministry of Culture, and some, in Cluj-Napoca, Caransebeș, and Iași. The meetings of the commission were completed with three round tables meant to facilitate dialogue with the local communities interested in patrimony issues Thus, I shall speak of the manner in which archaeology is publicly perceived and the manner in which the National Commission of Archaeology is perceived inside the community of archaeologists.

Keywords: Public archaeology, monuments, patrimony, legislation
\end{abstract}

$\mathbf{I}$ shall only discuss today a few of the problems of archaeology in Romania from the perspective of my one-year experience as member and vicepresident of the National Commission of Archaeology. I do not claim that my observations are generally true, that my diagnostics for the identified problems are correct, or that I am the one to suggest solutions that would in any way improve the legislative chaos governing our work or allow us to overcome the blockages that plague Romanian archaeology. My goal here is more modest and my intention is but to attempt to systematize the endless discussions during the meetings and round tables of the year that has just passed. Thus, I shall speak of the manner in which archaeology is publicly perceived and the manner in which the National Commission of Archaeology is perceived inside the community of archaeologists.

A novelty in the activity of the commission last year was the fact that its members have traveled to different centers in the country in order to become acquainted with the local archaeological realities and to establish direct contacts with the archaeologists in those respective regions of the country. While in the past the meetings of the commission were always held in Bucharest, in the building of the Ministry of Culture, now some were held, at the initiative of the commission's president, in Cluj-Napoca, Caransebes, and Iași. The meetings of the commission were completed with three round tables meant to facilitate dialogue with the local communities interested in patrimony issues (including archaeologists, museographers, teachers, employees of the County Directions for Culture, and police officers involved in patrimony protection).

THE ARCHEOLOGISTS AND THE MONUMENTS

\section{Sorin Nemeti}

University Babeș-Bolyai of Cluj-Napoca, Romania sorinnemeti@yahoo.com

DOI: $10.14795 /$ j.v4i3.275

ISSN $2360-266 \mathrm{X}$

ISSN-L 2360 - 266X 
The meeting held at the National History Museum of Transylvania in Cluj-Napoca included a round table entitled Archaeology and restoration. The temptation of reconstructing the monuments, Cluj-Napoca, 28 October 2016. It brought together the members of the commission and several local specialists in the field of patrimony protection, including architects (though the latter were not very numerous). One should note the presence of Mrs. Oana Bogdan, secretary of state. Several main ideas should be mentioned: the general tone of the speakers was public lamentation and the blaming of anonymous culpables, deploring the sad fate of the monuments that become ruined because the state does not protect and valorize them, due to the lack of funds and the low interest of local authorities in the matter. On the other hand, as previously mentioned, few architects were present despite the fact that a round table on the same topic had been organized by them the day before, attended by few archaeologists. The case is symptomatic for the lack of dialogue between these two professional groups, i.e. architects and archaeologists, who still meet in the field of research, protection, conservation, restoration, and valorization of monuments.

Returning to the relation between archaeologists and monuments, one can note two perfectly opposite attitudes: the archaeologists' lack of interest in and lack of responsibility for the discovered edifices and walls on the one hand and the local authorities' joyful abandonment of the same elements, though they wish to construct kitsch archaeological parks through megalomaniac projects. Any person performing archaeological excavations in a classical or medieval site should be aware from the very beginning of the fact that he/ she will almost certainly discover masonry structures and thus must take into account if not a project at least solutions for the primary conservation of such vestiges. Due to the sub-financing of this field of study, I do not know what these solutions are: covering the finds with soil, their conservation in situ with slabs of cement or actual reconstruction. Local authorities seem to prefer reconstruction, as they wish to build antiquity-themed Disneylands in their back yards, to populate with reenactors and thus increase the tourist attractiveness of the area. I only wish to remind my colleague archaeologists who perform researches on sites revealing masonry structures that we are the ones who uncover them and are thus responsible for their future. Such patrimony goods cannot be abandoned to wild nature, nor can they be transformed into the motherland's kitsch monuments. We must open dialogue with the local authorities that decide in such matters and explain to them that these monuments are valuable as they are, why they must not be reconstructed as they once stood and why they should not be drowned in stage props.

\section{TOO FEW ARCHAEOLOGISTS}

The meeting held on 22 February 2017 in Caransebeș, at the Museum of Ethnography and the Border Regiments included the round table entitled How many are we? An initiative of the National Commission for Archaeology for public archaeology. Discussions revolved round answers to the question in the title, namely if the number of practicing archaeologists recorded in the National Registry of Archaeologists is sufficient for covering the demands of a market opened by the needs of preventive archaeology. I have noted the incapacity of the participants of discussing the topic in a structured and meaningful manner, a trait that was characteristic to all three round tables and that is, I believe, a shared trait of the meetings of several professional groups in Romania (not only of archaeologists). Each person turns strictly to his own work, to his particular case and tends to generalize starting from there. Thus, it is not general issues, concepts, and solutions under discussion, but case studies of the type «look what happened to me on that occasion...». A related issue was that of how archaeologists become attested and how they are recorded in the registry. In my opinion, access should be made easier for junior archaeologists and one's subsequent evolution towards the titles of specialist and, especially, expert, should be conditioned by the publication of the results of their researches. It is unacceptable that materials should pile up in museums and field documentation in the offices and current regulations should be followed in that those who do not publish the results of their researches in five years should lose the right of intellectual property over those materials. To my knowledge, nowhere in the world do archaeologists have eternal intellectual property rights over the discovered goods. In Romania, one even finds ridiculous cases when archaeologists still hold scientific rights until pension, sometimes even after, and even more, they transmit those rights to their followers or heirs.

I thus believe that one solution is to enlarge the base of the pyramid of attested archaeologists and, in fact, to build this pyramid to a proportion of $3 / 2 / 1$ among junior archaeologists, specialists, and experts in the field. In order to reach these proportions, it is not enough to enlarge the base, but access should also be restricted to the upper levels, and this can only be done based on scientific criteria. Presence on archaeological sites is important, decisive even for field archaeologists, but they must also prove that they understand what is excavated there. Archaeologists understand their own excavations and translate them to their colleagues only through scientific publications. One is not a specialist or, even less so, an expert otherwise, no matter how many thousands of field work hours one accumulates.

Application files and quantitative criteria are insufficient and these criteria can be bent, as I have exemplified before. I suggest that access to the category of expert should rely on the candidate presenting an extended study of one of his/her own excavations (not necessarily published, but like the portfolio of architects) and defending it publicly in front of the National Commission of Archaeology. We shall thus restrict the number of experts who have reached that title having published just «one book».

\section{ARCHEOLOGISTS AND THE UNRECORDED PATRIMONY}

The most recent commission meeting took place in Iași on April 28th 2017, at the Al. I. Cuza University and the Iași Institute of Archaeology of the Romanian Academy. The round table entitled Archaeology in the eastern-Carpathian region. A necessary SWOT analysis: the area of Moldavia in the national and European archaeological environments. The 
discussion started from an observation made while releasing authorizations for systematic and preventive archaeological researches, namely the fact that archaeologists are rather few in Moldavia compared to the national context. What is the origin of this abstention of the archeological community from Moldavia? Why are there so few systematic researches applying for financing from the Ministry of Culture? The speakers, many off topic, have contributed to the general idea that the archaeological patrimony in the counties of Moldavia is poorly identified and catalogued. The main consequence of this is the absence of archaeological supervision of works requiring in depth interventions and the absence of preventive archaeological researches. As the sites are not identified and protected through their inclusion in the List of Historical Monuments and the National Archaeological Repertory, the county culture departments and the Regional Commissions of Historical Monuments have no instruments to protect them or provide for their preventive research. A secondary consequence is the decrease of field activity for archaeologists. Naturally, the problem is not so simple as I have abstracted it here: the lack of excavations is also caused by the fact that the beneficiaries do not follow the patrimony protection laws, the patrimony police are incapable of monitoring all these disorders and of enforcing the regulations, maybe also by the lethargy and lack of involvement of some of the members of the archaeological community.

\section{CONCLUSIONS}

This abstract of the National Commission of Archaeology excursions and associated round tables aims at showing, on the one hand, how this young and de-legitimized commission has opened up to the restricted public of the community of archaeologists and people interested in patrimony protection.

The most important conclusion after all of these debates is that the specialized legislation is obsolete, both the «organic law» governing our activity, i.e. OG 43 of 2000 and the other regulations and procedures.

Why can the laws in other specialties be adapted to actual situations but in archaeology they cannot? In 2000 our society's current need for preventive archaeology did not exist. Hundreds of authorizations were not applied for each month. In the context in which preventive researches develop progressively, the reflex reaction of the centralized state has been to control them to the maximum and thus a totalitarian logic has been reached, leading to excessive bureaucratization. A sentence of everyone's lips is that the authorization release procedure must be simplified, though nobody can suggest an acceptable solution. "Solving the issue of authorization" must not be done in an amateurish fashion or in a hurry. I believe that the archaeologists must meet with jurists and find a way to amend OG 43 of 2000 in accord with existing legislation and with the real needs of our profession. In Romania, the laws cannot anticipate social developments, but they must at least regulate after they take place, to match these developments retrospectively. My conclusion is that we have a series of laws of yesterday for the archaeology of today. I know that this is a platitude, that I have discovered that the grass is green, but now we must measure in order to make things work. 